\title{
TRABALHO, EDUCAÇÃO E SAÚDE NA PERSPECTIVA DAS CONCEPÇÕES DE ENFERMEIROS EM ATIVIDADE DOCENTE
}

\author{
WORK, EDUCATION AND HEALTH FROM THE PERSPECTIVE OF THE CONCEPTION OF NURSES \\ IN THE TEACHING ACTIVITY
}

\author{
Simone Mendes Carvalho ${ }^{1}$ \\ Graciele Oroski Paes ${ }^{2}$ \\ Joséte Luzia Leite ${ }^{3}$
}

Resumo Este artigo busca apresentar e discutir as concepções de enfermeiros docentes sobre trabalho, educação e saúde. Para tal, foram entrevistados sete professores de enfermagem que atuam em uma instituição de ensino superior no estado do Rio de Janeiro. Os relatos obtidos apontaram para dupla face do trabalho, relacionado concomitantemente com satisfação e sofrimento, identificados, respectivamente, pela criatividade/autonomia e obrigatoriedade/precarização. Foi identificada, ainda, a influência das políticas neoliberais no trabalho nas áreas da educação e saúde. Questões relacionadas à educação se concentraram na discussão da construção coletiva dos conhecimentos e da formação cidadã. Já com relação à saúde, as concepções dos docentes entrevistados apresentaram conceitos de promoção da saúde e seus determinantes. As interfaces entre trabalho, educação e saúde foram percebidas sob aspectos diferenciados, chamando atenção para a necessidade de múltiplas transformações nas três áreas para efetivação da qualidade destas relações.

Palavras-chave trabalho; educação; enfermagem.
Abstract This article seeks to present and discuss the concepts nursing teachers have about work, education and health. To this end, we interviewed seven nursing teachers who work at a higher education institution in the state of Rio de Janeiro. The reports that were obtained pointed to the double side of the work, related, concurrently, with satisfaction and distress, identified, respectively, by creativity/autonomy and obligation/insecurity. The influence neoliberal policies have on employment and in the education and health areas was also noticed. Issues related to education focused on discussing the collective construction of knowledge and civic education. Regarding health, meanwhile, the perceptions of the educators who were interviewed involved concepts of promoting health and its determining factors. The interfaces among work, education and health were perceived in different ways, calling attention to the need for multiple changes in these three areas in order for it to be possible to achieve quality in these relations.

Keywords work; education; nursing. 


\section{Introdução}

Este estudo nasce da sensibilização das autoras para a reflexão sobre as relações entre trabalho, educação e saúde, tendo como ponto de partida as concepções de enfermeiros docentes, uma vez que se trata de profissionais que lidam, cotidianamente, nas suas atividades de trabalho, com a interface educação/saúde.

$\mathrm{Na}$ perspectiva ontológica de trabalho, o homem modifica a natureza pelo trabalho e, neste processo, ele se modifica, desenvolve suas potencialidades, se realiza e se humaniza.

Neste sentido, Marx (1963) afirma que, antes de tudo, o trabalho é um processo em que participam o homem e a natureza, processo em que o ser humano, com sua própria ação, impulsiona, regula e controla o intercâmbio material com a natureza. Atuando assim sobre a natureza externa e modificando-a, ao mesmo tempo, o homem modifica sua própria natureza.

$\mathrm{O}$ trabalho se configura como atividade genuinamente humana porque não é realizado por instinto. Ele acontece como uma atividade consciente, consequência de uma necessidade, do movimento teleológico do trabalho, exclusivamente humano, quando infere que o homem figura na mente sua construção antes de transformá-la em realidade. No fim do processo do trabalho, aparece um resultado que já existia antes idealmente na imaginação do trabalhador (Marx, 1963).

Na sociedade capitalista, o trabalho se estabelece por relações entre homens livres, diferentemente do modo escravagista de produção. Os homens são livres para vender e comprar suas forças de trabalho, mas trata-se de uma relação verticalizada, porque o trabalhador precisa vender o seu trabalho para alguém como forma de subsistência e direito ao consumo.

O discurso liberal classifica o trabalho como virtuoso, imbuindo sentimentos de culpa e frustração naquele que não trabalha. Este discurso passa a legitimar o direito ao consumo e à propriedade privada, fazendo com que a acumulação de lucro socialmente aceita tenha sua origem na apropriação da natureza, dos produtos e da força de trabalho do trabalhador.

O caráter alienado do trabalho se apresenta ao se perceber que "quanto mais o trabalhador se desgasta no trabalho, tanto mais poderoso se torna o mundo dos objetos por ele criados em face dele mesmo, tanto mais pobre se torna a sua vida interior e tanto menor ele pertence a si próprio" (Max 1963, p. 23). Ainda neste sentido, Marx (1963) fala da alienação do trabalho à medida que ele não pertence ao trabalhador, que trabalha para outrem. Então, no trabalho, o trabalhador não pertence a si mesmo, mas a outra pessoa.

Considerando o tempo histórico em que Marx (1963) descreve o trabalho alienado, observando operários de fábricas na produção capitalista de bens de consumo, podemos ter a impressão de que o processo de trabalho dos 
profissionais da saúde e da educação no século XXI não faz parte deste contexto. A maioria destes profissionais, inseridos no mercado de trabalho, não produz objetos, mas são prestadores de serviço.

Nesse sentido, Kuenzer (2004) descreve o trabalho de enfermeiros, professores e outros profissionais liberais, ressaltando uma característica muito peculiar: a sua natureza não-material, já que não é possível separar produtor do seu produto.

Nesse contexto, o trabalho pode ser concebido de duas maneiras: a partir de suas características mais gerais, que independem do modo de produção e que, portanto, são intrínsecas a sua natureza; ou a partir das formas históricas que vai assumindo, de acordo com o desenvolvimento das forças produtivas. Estas duas concepções não se opõem, e sim guardam uma relação dialética entre si, em que, ao mesmo tempo, se negam e se afirmam, configurando a dupla face do trabalho: qualificador e prazeroso e, simultaneamente, desqualificador, explorador, causador de sofrimento.

Os serviços de saúde, como os demais, sofreram os impactos da crise do capitalismo do final do século XX, sendo forçados a se reorganizarem para garantir a competitividade e assegurar a acumulação, adotando as estratégias próprias da reestruturação produtiva. Assim, combinaram complexificação tecnológica com redução de força de trabalho, hierarquizada segundo novas formas de articulação entre qualificação-desqualificação e quantidade de trabalhadores, além de incorporarem mecanismos de descentralização, em particular a terceirização. Neste contexto, os profissionais de saúde vendem sua força de trabalho para objetivar um resultado com o qual, na maioria das vezes, não concordam. Através de seu trabalho, geram um produto que é fruto de sua alienação, de sua própria transformação em mercadoria, e não fruto do projeto de intervenção na sociedade (Kuenzer, 2004).

A divisão do trabalho na saúde se dá, por um lado, pela consolidação nos serviços de saúde das corporações profissionais e, de outro, pela especialização do saber e, consequentemente, do trabalho em saúde. A organização parcelar do trabalho fixa os trabalhadores em uma determinada etapa do projeto terapêutico. A superespecialização e o trabalho fracionado fazem com que o profissional de saúde se aliene do próprio objeto de trabalho. Desta forma, ficam os trabalhadores sem interação com o produto final da sua atividade laboral, mesmo que dele tenham participado pontualmente. Como não há interação, não haverá compromisso com o resultado do seu trabalho (Franco; Bueno; Merhy, 2006).

Para Saviani (1994), muitas são as relações entre educação e trabalho: ao pensar educação como escola, a tendência dominante é situar a educação no âmbito do não-trabalho, atribuindo um caráter não produtivo à educação, que passa a ser entendida como um bem de consumo. Outra percepção da relação entre educação e trabalho coloca a educação como decisiva para o 
desenvolvimento econômico, potencializadora do trabalho e qualificadora da mão-de-obra.

No campo da educação na saúde, a maioria dos cursos técnicos, universitários, de pós-graduação e as residências forma profissionais distantes das necessidades de saúde da população e de organização do sistema. Além disso, enquanto em algumas regiões do país há uma grande oferta de cursos de formação na área da saúde, em outras eles quase não existem. Para completar, existem muitos educadores e orientadores de serviços que estão desatualizados e precisam se apropriar de novos modelos de ensinar. É nesse contexto que o Ministério da Saúde (Brasil, 2005a) propõe a educação permanente como estratégia de transformação das práticas de formação, de atenção, de gestão, de formulação de políticas, de participação popular e de controle social no setor saúde.

Nesse sentido, o presente texto tem por objetivo suscitar reflexões sobre o trabalho dos profissionais de saúde que atuam na formação de novos profissionais, no caso enfermeiros docentes, e sua relação com a educação e a saúde.

Propõe-se conhecer as concepções destes profissionais sobre trabalho, educação e saúde como forma de melhor compreender o contexto em que atuam enfermeiros no exercício do trabalho na área da educação. E, ainda, contextualizar estas concepções à luz da dupla face do trabalho como um espaço contraditório onde convivem sentimentos de satisfação no trabalho, produção de conhecimentos, oportunidade de criação, emancipação e, ao mesmo tempo, dilemas, sentimentos de sobrecarga e sofrimento no trabalho.

\section{Metodologia}

Trata-se de um estudo qualitativo e descritivo, uma vez que a identificação das concepções de enfermeiros docentes sobre as relações entre trabalho, educação e saúde, interage com o universo dos significados, motivações, aspirações, crença e valores, que não pode ser quantificado (Minayo, 1996). Além disso, tenta-se compreender e interpretar a realidade, sem nela interferir para modificá-la (Rudio, 2002).

Foram entrevistados sete enfermeiros docentes, em uma instituição superior de ensino no estado do Rio de Janeiro. Foi solicitado que os participantes do estudo falassem livremente sobre suas concepções sobre trabalho, depois sobre educação e a seguir sobre saúde. Por fim, questionou-se, com base nas experiências profissionais de cada um, que relações eles percebiam entre trabalho, educação e saúde. As entrevistas aconteceram nos meses de maio e junho de 2009.

Os princípios éticos para pesquisa foram respeitados, com base na Resolução n. ${ }^{\circ}$ 196/96 do Conselho Nacional de Saúde. Aos entrevistados foram 
garantidos a participação voluntária e o anonimato, sendo utilizados pseudônimos para cada um deles. A pesquisa em tese foi submetida à apreciação do Comitê de Ética da instituição, sendo o mesmo aprovado sem restrições.

Com base nos relatos obtidos, buscou-se apresentá-los e analisar seus conteúdos, estabelecendo articulações entre os dados e os referenciais teóricos.

\section{Resultados e discussão}

O tempo de atividade docente dos enfermeiros entrevistados variou de um a 15 anos. Além da docência, seis deles realizavam atividades na área assistencial, três participavam também na gestão de serviços de saúde e um na gestão educacional. Todos exerciam a prática com estudantes, sendo que cinco deles estavam inseridos no universo hospitalar e dois na atenção básica, especificamente no Programa Saúde da Família.

\section{Concepções sobre o trabalho}

Questionados sobre o que pensavam sobre 'trabalho', obtivemos relatos diversificados, que evidenciaram a 'dupla face' do trabalho: de um lado, qualificador, prazeroso, com possibilidades de intervenções criativas e transformadoras; de outro, obrigatório, intensificado, desgastante, desqualificado e explorado (Kuenzer, 2004).

A face positiva do trabalho foi construída por aspectos como a possibilidade de relação entre teoria e prática, oportunidade de crescimento, satisfação, manifestação da criatividade e habilidades, apresentados nos relatos que se seguem:

Atividade profissional que proporciona satisfação, crescimento intelectual e habilidade técnico-científica. Requer do indivíduo dedicação, entusiasmo, criatividade e busca crescente (Juliana).

Oportunidade de estar inserida em um contexto social, colocando em prática minhas concepções, meus ideais e minhas habilidades em relação à minha profissão (Rosana).

Interação entre educação e prática, ou seja, aplicabilidade de conhecimentos na prática profissional (Marcelo).

Atividades de conciliação da prática, teoria e pesquisa. Desejo que sejam realizadas por prazer (Patrícia). 
Contextualizando a positividade de trabalho, remete-se à demanda por renormatização e inventividade e ao caráter não totalmente padronizável da vida e do trabalho. Trata-se do trabalho, como manifestação da vida, e, por isso, uma atividade que não é inteiramente heterodeterminada. $\mathrm{O}$ trabalho não pode ser reduzido à prescrição (Brito e Athayde, 2003). O conceito ampliado de atividade, segundo Schwartz (2000) recusa a neutralidade das dimensões subjetivas da ação e permite compreender o trabalho como um lugar permanente de escolhas, mesmo que microescolhas, de debate de normas e valores.

A possibilidade de expressão da criatividade, das habilidades e de intervenções, trazendo satisfação para o trabalho do enfermeiro docente, é contextualizada em uma das dimensões do trabalho do professor. Sobre isso, Basso (1998) aponta a autonomia garantida pela própria particularidade do trabalho docente, onde o professor escolhe metodologias, faz seleção de conteúdos e de atividades pedagógicas mais adequadas a seus estudantes, segundo seus interesses ou necessidades e dificuldades.

A ideia do trabalho, estabelecendo articulação entre teoria e prática, suscita a reflexão crítica de que a prática se torna uma exigência da relação teoria/prática, sem a qual a teoria pode ir virando falácia e a prática, ativismo (Freire, 2005).

A face negativa do trabalho foi evidenciada na expressão dos aspectos que envolvem a obrigatoriedade para o sustento, a precarização e exploração do trabalho, observado no relato de 'Cristina' e 'Pedro'.

Atividade desenvolvida com o objetivo de sustento próprio (Cristina).

Fonte de sustento, reforma agrária, exploração, baixos salários e precarização (Pedro).

Atualmente, não é raro se observar profissionais de saúde submetidos a jornadas de trabalho exaustivas, com baixos salários e precárias condições de trabalho, como falta de material, número excessivo de doentes etc. Segundo Sobrinho (2006), a terceirização e a privatização também fazem parte deste setor, com acentuada presença das cooperativas que oferecem baixos salários, retratando a saúde como fator de lucro. A carga horária excessiva de trabalho desses profissionais e a insatisfação com suas atividades são, em grande parte, consequências da precarização do trabalho que, muitas vezes, é visto como uma obrigatoriedade.

Rocha e Ferreira (2005) relacionam esta precarização com a limitação de investimentos no setor saúde, inferindo que a efetivação do Sistema Único de Saúde tem esbarrado na desestruturação da rede de saúde nos seus diferentes níveis de atenção. É observado que grande parte da assistência à saúde, principalmente em níveis de maior complexidade, vem sendo oferecida 
pela rede privada, mediante convênios, cujo objetivo principal é o lucro e onde a precarização do trabalho dos profissionais da saúde também se faz presente.

\section{Concepções sobre a educação}

Ao solicitar aos entrevistados que falassem sobre educação, obtivemos três relatos que enfocaram a construção coletiva dos conhecimentos, a interação entre as pessoas e o meio:

Construção de conhecimento coletivamente (Marcelo).

Espaço de discussão social para produção dos conhecimentos, agregação e aprimoramento dos mesmos, levando-se em consideração toda uma análise cultural (Rosana)

Conhecimentos alcançados através de práticas, trocas de informações pessoapessoa, pessoa-ambiente, pessoa-culturas (Patrícia).

A construção coletiva dos conhecimentos requer inventar novas relações entre os sujeitos envolvidos nos processos educacionais, através da utilização de métodos ativos de ensino-aprendizagem, em múltiplos cenários de cuidado (Moraes e Lopes, 2009). Processos participativos e inclusivos de todos os segmentos envolvidos no ensino se constituem importantes estratégias para o envolvimento e motivação do grande número de atores que deverão impulsionar inovações e transformações na educação. Para cumprir suas novas funções, a escola deverá se constituir em um espaço de educação permanente de professores, trabalhadores e estudantes (Brasil, 2005b).

Dois entrevistados relacionaram a educação com o desenvolvimento individual:

A educação é essencial à formação do homem. A meu ver, o requisito mais importante para a formação e a perpetuação do ser humano é a educação (Paula).

Necessidade do ser humano para poder evoluir no seu desenvolvimento (Cristina).

Além da formação do indivíduo, três relatos chamaram a atenção para a formação do cidadão, com vistas ao desenvolvimento social:

Além de formar o homem, deve formar o cidadão (Juliana).

Desenvolvimento pessoal, da cidadania e da sociedade (Pedro). 
A educação para formar o cidadão, preocupado com aspectos éticos e desenvolvimento social, como suscitado nos relatos anteriores, é coerente com o que Freire (2005) chama de 'pensar certo', que vai contra a reprodução dos conhecimentos. Transformar a experiência educativa em puro treinamento técnico é amesquinhar o que há de fundamentalmente humano no exercício educativo: o seu caráter formador. Ao respeitar a natureza do ser humano, o ensino dos conteúdos não pode dar-se alheio à formação moral do educando. Não há pensar certo à margem dos princípios éticos. Quem pensa certo está cansado de saber que as palavras a que falta a corporeidade do exemplo pouco ou quase nada valem. Pensar certo é fazer certo, é educar para cidadania (Freire, 2005).

Cabe ressaltar que a ideia de cidadania coletiva, segundo Frigotto e Ciavatta (2003), implica o resgate da individualidade como parte de um coletivo e, portanto, como sujeito político. A concepção de cidadania coletiva está muito distante da noção mercantil do cidadão produtivo, já que este deve possuir qualidades para inserção em uma economia de mercado que o aliena de sua generalidade em comunhão política com os demais homens, para submetê-lo aos ditames da produtividade exigida pela reprodução do capital.

\section{Concepções sobre a educação}

Com relação à saúde, os entrevistados referiram-se ao equilíbrio entre os fatores biológicos, psicológicos, sociais, entre outros, além de apontar alguns dos determinantes de saúde, como pode ser evidenciado nos relatos que se seguem:

Equilíbrio entre os fatores internos e externos que envolvem trabalho, educação, lazer, economia, estilo de vida etc. (Juliana).

Trabalho, educação, lazer, assistência à saúde, igualdade (Pedro).

Um processo de equilíbrio entre o biológico, social e o antropossocial (Rosana).

Bem-estar físico e psicossocial (Marcelo).

Bem-estar biopsicossocial e espiritual para as pessoas, ambiente e cultura (Patrícia).

Requisito necessário para manutenção da vida. O indivíduo que promove a saúde preventiva não adoece, investe na qualidade de vida (Paula). 
Não é apenas a ausência de doença, mas sim algo que é essencial ao ser humano para desenvolver suas atividades cotidianas. Sem ela é impossível ter condições de uma vida social e o psicológico também fica prejudicado (Cristina).

Observa-se nos relatos dos docentes o conceito de determinantes multifatoriais da saúde e a relação com a promoção da saúde. A saúde e o adoecer são formas pelas quais a vida se manifesta. Correspondem a experiências singulares e subjetivas, impossíveis de serem reconhecidas e significadas integralmente pela palavra. Contudo, a constatação de que os principais determinantes de saúde são exteriores ao sistema de tratamento não é novidade. Porém, oficialmente, é bem recente a formulação de um discurso sanitário que afirme a saúde em sua positividade. A Conferência Internacional sobre Promoção de Saúde, realizada em 1986 em Ottawa, postula a ideia da saúde como qualidade de vida resultante de complexo processo condicionado por diversos fatores, tais como, entre outros, alimentação, justiça social, ecossistema, renda e educação (Czeresnia, 2003).

\section{Relações percebidas entre trabalho, educação e saúde}

Ao solicitar que relacionassem trabalho, educação e saúde, a partir de sua prática profissional, uma entrevistada referiu não encontrar articulação destes elementos no seu cotidiano de trabalho:

Não há nenhuma integração entre trabalho, educação e saúde (Juliana).

Contraditoriamente, quatro entrevistados referiram a percepção de integração entre trabalho, educação e saúde, durante sua prática profissional:

Trabalho, educação e saúde caminham juntos na minha prática profissional, estão interligados e se complementam durante a prática (Marcelo).

Tento conciliar as três instâncias em minhas atividades, seja onde for (Patrícia).

Percebo a relação na minha prática da seguinte forma: O trabalho é suporte para manutenção da saúde. Sem trabalho, o homem padece e sem educação não se consegue trabalho para manter-se saudável. São conceitos importantes pelos quais o homem nasce, cresce, evolui, enquanto puder, com qualidade de vida, conquistada através da educação, prevenção e promoção da saúde (Paula).

A saúde está presente em todos os aspectos. A educação é um processo contínuo de saúde e trabalho. Para você educar, ensinar, você deve estar bem consigo mesmo; 
senão, algo pode interferir nos seus ensinamentos. O trabalho é essencial para a vida do ser humano. Sem esse trio não conseguiremos chegar aonde chegamos em termos profissionais e em anos de vida (Cristina).

A relação percebida entre trabalho, educação e saúde nestes relatos se apresentou em diversas dimensões. Neste sentido, Carvalho (2005) discute que trabalho, educação e saúde possuem conceitos distintos, mas, quando desenvolvidos, são dependentes no que diz respeito às suas ações.

Uma entrevistada relatou sua percepção de indissociabilidade entre trabalho, educação e saúde, mas reconheceu a dificuldade maior de integração do elemento 'saúde' neste processo:

Na minha vivência, trabalho, educação e saúde devem ser indissociáveis. Isto é muito mais fácil, no meu caso, entre trabalho e educação, pois no caso da saúde, nem sempre encontramos o equilíbrio tanto na parte dos profissionais, quanto na parte dos usuários. São relações que sofrem quebras durante o processo, por necessitarem estar articuladas a todo o momento e nem sempre isto é possível (Rosana).

A percepção de dificuldade de articulação da saúde com trabalho e educação, resultado de 'quebras durante o processo', como é apontada pela entrevistada 'Rosana', pode estar relacionada com a complexidade da organização e produção da saúde, ressaltando, ainda, o atual movimento de mudança de paradigma assistencial.

A mudança no modelo de atenção à saúde, uma das grandes lutas advindas do movimento de Reforma Sanitária, permanece como utopia concretizável (Pires, 2005). Pretende-se transcender a abordagem curativa, hospitalocêntrica, fragmentada em especialidades, fundada em processos de trabalho rigidamente divididos, alienados e na hegemonia do médico sobre a equipe de saúde (Campos, 2006; Pires, 1989). Em seu lugar, propõem-se abordagens interdisciplinares, com resgate da integralidade da atenção, centradas na saúde, na comunidade, no fortalecimento de redes solidárias, na participação social e na pessoa como sujeito do seu processo saúde-doença (Pires, 1989).

Tal ideário, fundado nos princípios do Sistema Único de Saúde, sofre influência das profundas mudanças que vêm ocorrendo na estrutura da sociedade, nos valores e hábitos de saúde da população, como consumismo e medicalização dos problemas sociais, em que as questões de ordem pública são tomadas restritamente, apenas sob a ótica da dimensão privada, enfatizando-se o tratamento das enfermidades com o fim em si (Boaventura Santos, 1997; Fleury, 1997; Offe, 1991), além da própria formação e prática dos profissionais (tecnicista, cartesiana e positivista), inserindo-se no contexto estrutural mais amplo de conformação das relações de ajuda-poder nas políticas sociais (Pires, 1989). 
Um dos entrevistados relacionou o desemprego e a baixa escolaridade como determinantes da saúde da população e apontou a política neoliberal como geradora de iniquidades e dificuldade de acesso ao trabalho, à educação e à saúde:

Percebo que os determinantes do processo saúde-doença estão intimamente relacionados aos elevados números de desempregados, bem como o baixo nível de escolaridade da população brasileira. A iniquidade de acesso às políticas públicas retrata as desigualdades que promovem a pobreza, a fome e a doença. A concentração de renda e a política econômica neoliberal, adotada praticamente em todo o mundo, são fatores determinantes do desemprego e da iniquidade de acesso à educação e aos serviços de saúde de boa qualidade. Portanto, a política econômica neoliberal é antagônica ao trabalho digno para todos e às políticas sociais (Pedro).

Soares (2003) aponta a manifestação do impacto das políticas neoliberais no mundo do trabalho através do desemprego e da precarização das condições de trabalho. A autora refere-se a um termo denominado de 'desfiliação', que seria a situação de determinados indivíduos de flutuação na estrutura social, pois não encontram um lugar designado devido ao desemprego e instabilidade de empregos temporários e ocupações provisórias.

As políticas de ajuste neoliberal retratam um desastre social que provocam consequentemente um desajuste social e um desajuste global. Isso porque essas políticas trouxeram um agravamento das desigualdades, com o surgimento de novas condições de exclusão social em grupos que antes eram 'incluídos' a partir de sua inserção no mercado de trabalho. Os países mais pobres da periferia sofreram impactos consideráveis nesse ajuste neoliberal do ponto de vista social com a ideia de 'globalização da pobreza'. Outra consequência dessas políticas neoliberais foi a instabilidade, gerada pela terceirização do funcionalismo público, o que reflete em trabalhadores insatisfeitos e sem compromisso com a qualidade e resultado de suas ações, como, por exemplo, no caso da saúde que é um serviço essencial e fundamental à vida. $\mathrm{O}$ direito de cidadania vem sendo substituído pelos 'atestados de pobreza', que permitem o acesso a precários e malfinanciados serviços públicos (Soares, 2003).

Neste contexto, João Antônio Felício, presidente da Central Única dos Trabalhadores, na $3^{\text {a }}$ Conferência Nacional de Gestão do Trabalho e da Educação na Saúde, em 2006, disse não concordar com o discurso 'neoliberal' que o trabalho dignifica o homem, completando que o que realmente dignifica o trabalhador é o emprego bem remunerado que dê condições de vida. Condenou a precarização das relações de trabalho - contratação verbal, apadrinhamento e terceirização (Dominguez, 2006). 


\section{Conclusão}

Buscou-se demonstrar neste artigo que as concepções sobre trabalho, educação, saúde e suas relações foram variadas entre enfermeiros docentes entrevistados. O caráter dialético do trabalho como prazeroso e, ao mesmo tempo, causador de sofrimento esteve presente nos relatos obtidos. A face positiva do trabalho foi evidenciada, especialmente, pela liberdade para criação e autonomia do exercício da docência. Aspectos relacionados à face negativa do trabalho foram relacionados à sua obrigatoriedade como fonte de sustento e à precarização.

As concepções sobre educação se relacionaram, principalmente, à construção coletiva dos conhecimentos e a formação individual e para o exercício da cidadania. Já com relação à saúde, foi evidente no relato de todos os enfermeiros entrevistados a determinação multifatorial e conceitos de promoção da saúde.

Foi possível observar, ainda, com base no presente estudo, a percepção da influência das políticas neoliberais no mundo do trabalho, assim como na educação e saúde.

Por fim, é importante ressaltar que a relação entre trabalho, educação e saúde necessita e vem sofrendo mudanças. Estas mudanças propostas envolvem as ações para consolidação do Sistema Único de Saúde, a formação dos profissionais de saúde e novas formas de se pensar o trabalho. É preciso resgatar a humanidade e o prazer do trabalho para educação, do trabalho para a saúde, da educação para o trabalho, da educação para saúde, da saúde para o trabalho e para educação. Isto necessita de intervenções infra e supraestruturais. É preciso organizar ainda mais a atenção básica e garantir sua relação com os demais níveis de atenção. É preciso investir em educação permanente.

Para Paes (2006) é preciso formar profissionais de saúde que saibam trabalhar em equipe e atuar com responsabilidade social, compromissados com a cidadania, com o cuidar integral da saúde, com capacidade para tomar decisões, com habilidades de comunicação, com competências técnico-científicas, ético-políticas e socioeducativas. São muitas as frentes de propostas com objetivos convergentes. O fato é que é preciso caminhar, uma vez que as conquistas não estão no início, nem na chegada. Elas se colocam durante o caminho. 


\section{Notas}

1 Professora adjunta I do Centro Universitário Norte do Espírito Santo, da Universidade Federal do Espírito Santo (Ceunes/Ufes), São Mateus, Espírito Santo, Brasil. Doutora em Saúde Pública pela Escola Nacional de Saúde Pública Sergio Arouca (Ensp/Fiocruz). <simonemendes@ceunes.ufes.br>

Correspondência: Avenida Espera Feliz, 228, Guriri Norte, São Mateus, Espírito Santo, Brasil, CEP 29946-600.

2 Professora Assistente do Departamento de Enfermagem Fundamental da Escola de Enfermagem Anna Nery, da Universidade Federal do Rio de Janeiro (DEF/EEAN/UFRJ), Rio de Janeiro, Brasil. Doutoranda em Enfermagem pela Escola de Enfermagem Anna Nery, da Universidade Federal do Rio de Janeiro (EEAN/UFRJ). < gracieleoroski@gmail.com>

3 Pesquisadora $1 \mathrm{~A}$ do CnPQ. Professora Titular Emérita da Universidade Federal do Estado do Rio de Janeiro (Unirio), Rio de Janeiro, Brasil. Doutora em Enfermagem pela Federação das Escolas Federais Isoladas do Estado do Rio de Janeiro (Fefierj).<joluzia@gmail.com>

\section{Referências}

BASSO, Itacy S. Significado e sentido do trabalho docente. Caderno Cedes, Campinas, v. 19, n. 44 , p. 19-22, 1998.

BRASIL. Ministério da Saúde. Secretaria de Gestão do Trabalho e da Educação na Saúde. Departamento de Gestão da Educação na Saúde. A educação permanente entra na roda. Série C. Projetos, Programas e Relatórios. Brasília: Ministério da Saúde, 2005a.

Ministério da Saúde. Curso de especialização em ativação de processos de mudança na formação superior de profissionais de saúde. Caderno do Especializando. Rio de Janeiro: Fiocruz, 2005b.

BRITO Jussara.; ATHAYDE, Milton. 2003. Trabalho, educação e saúde: o ponto de vista enigmático da atividade. Trabalho, Educação e Saúde, Rio de Janeiro, v. 1, n. 2, p. 239-265, 2003.

CAMPOS, Gastão S. W. Reforma da reforma: repensando a saúde. 3. ed. São Paulo: Hucitec, 2006.
CARVALHO, Gilson. Saúde: o tudo para todos que sonhamos e o tudo que nos impingem os que lucram com ela. Saúde em Debate, Rio de Janeiro, v. 29, n. 69, p. 99-104, 2005.

CZERESNIA, Dina. O conceito de saúde e a diferença entre prevenção e promoção. In: CZERESNIA, Dina.; FREIRAS, Carlos M. Promoção da saúde: conceitos, reflexões, tendências. Rio de Janeiro: Editora Fiocruz, 2003. p. 39-54.

DOMINGUEZ, Bruno. C. A desprecarização é urgente. Radis - Comunicação em Saúde, Rio de Janeiro, v. 46, p. 8-11,2006.

FLEURY, Sônia. Saúde e democracia: a luta do Cebes. São Paulo: Lemos editorial, 1997.

FRANCO, Tulio B.; BUENO, Wanderlei. S, MERHY, Emerson E. O acolhimento e os processos de trabalho em saúde: o caso de Betim, MG. In: MERHY Emerson E. et al. O trabalho em saúde: olhando e experienciando o SUS no cotidiano. 3. ed. São Paulo: Hucitec, 2006. p. 39-54. 
FREIRE, Paulo. Pedagogia da autonomia. 31. ed. São Paulo: Paz e Terra, 2005.

FRIGOTTO, Gaudêncio; CIAVATTA, Maria. Educar o trabalhador cidadão produtivo ou o ser humano emancipado? Trabalho, Educação e Saúde, Rio de Janeiro, v.1, n.1, p. 4560, 2003.

KUENZER, Acacia Z. Sob a reestruturação produtiva, enfermeiros, professores e montadores de automóveis se encontram no sofrimento do trabalho. Trabalho, Educação e Saúde, Rio de Janeiro, v. 2, n. 1, p. 239265, 2004.

MARX, Karl. O trabalho alienado. In: Economia política e filosófica. Tradução de Sílvia Patrícia. Rio de Janeiro: Melso, 1963. p. 151-163.

MORAES, Juliano T.; LOPES, Eliane M. T. A formação de profissionais de saúde em instituições de ensino superior. Trabalho, Educação e Saúde, Rio de Janeiro, v. 7, n. 3, p. 435-444, 2009.

MINAYO, Maria Cecília S. Ciência, técnica e arte: o desafio da pesquisa social. In: MINAYO, Maria Cecília S. et. al. Pesquisa social: teoria, método e criatividade. 6. ed. Petrópolis: Vozes, 1996. p. 9-29.

OFFE, Claus. Algumas contradições do Estado social moderno. In: Trabalho e sociedade: problemas estruturais e perspectivas para o futuro da sociedade do trabalho. Rio de Janeiro: Tempo Universitário, 1991. p. 113-131.

PAES, Graciele. O. et al. Saberes e práticas profissionais no espaço do ensino de enfermagem. Enfermagem Brasil, Rio de Janeiro, v. 5, p. 361-364, 2006.

PIRES, Denise. Hegemonia médica na saúde e na enfermagem. São Paulo: Cortez, 1989.
PIRES, Maria. R. G. M. Politicidade do cuidado e processo de trabalho em saúde: conhecer para cuidar melhor, cuidar para conformar, cuidar para emancipar. Ciência \& Saúde Coletiva, Rio de Janeiro, v. 10, n. 4, p. 1.025-1.035, 2005.

ROCHA, Solange.; FERREIRA, Verônica. Reformas do Estado e seguridade social: o caso da saúde. In: VILLELA, Wilza.; MONTEIRO, Simone. Gênero e saúde: programa saúde da família em questão. São Paulo: Abrasco/UNFPA/Arbeit Factor, 2005.

RUDIO, Franz. V. Introdução ao projeto de pesquisa científica. 30. ed. Petrópolis: Vozes, 2002.

SANTOS, Boaventura de S. Pela mão de Alice: o social e o político na pós-modernidade. 2. ed. São Paulo: Cortez, 1997.

SAVIANI, Demerval. O trabalho como princípio educativo frente às novas tecnologias. In: FERRETTI, Celso J. et al. Novas tecnologias, trabalho e educação: um debate multidisciplinar. 2. ed. Petrópolis: Vozes, 1994. p. 151-167.

SCHWARTZ, Yves. Le paradigme ergologique ou um métier de Philosophe. Toulouse: Octarès, 2000.

SOARES, Laura. T. O desastre social. Rio de Janeiro: Record, 2003.

SOBRINHO, Carlito; CARVALHO, Fernando.; BONFIM, Tárcyo. Condições de trabalho e saúde mental dos médicos de Salvador, Bahia, Brasil. Cadernos de Saúde Pública, Rio de Janeiro, v. 22, n. 1, p. 35-42, 2006.

Recebido em 09/02/2010

Aprovado em 15/03/2010 